Obituary

\title{
Arthur Schawlow(1921-99)
}

\section{Laser scientist}

Arthur Schawlow, co-inventor of the laser and one of the great figures of this century in optical science, died on the 28 April 1999. The laser has revolutionized optical science and its applications, providing powerful new technology in a variety of areas such as communications, cutting and welding, information storage and precision measurements. Schawlow also carried out many innovative experiments of high precision and high resolution, and pioneered a variety of new experimental optical techniques.

Schawlow was born in Mount Vernon, New York, in 1921. His father had emigrated to the United States from Latvia and his mother came from Canada. At her urging, the family moved to Toronto when Arthur was three. As an outstanding student, the young Schawlow was able to obtain a scholarship to the University of Toronto and proceed to a $\mathrm{PhD}$ degree. His thesis, supervised by Professor Malcolm Crawford, involved high-resolution spectroscopy using atomic beams, and the equipment required much ad hoc and money-saving improvisation. His later work was carried out in the United States - at Columbia University, Bell Telephone Laboratories and Stanford University, where he worked until shortly before his death aged 77 .

In college, Schawlow also played the clarinet and helped to organize the Delta Jazz Band. Over his lifetime, he assembled a remarkable collection of jazz recordings, now in the Stanford archives.

After finishing his $\mathrm{PhD}$, Schawlow went to Columbia University in 1949 to work with me on microwave spectroscopy, supported by a fellowship. I was quickly impressed by Arthur's insight and creativeness. He worked on a variety of

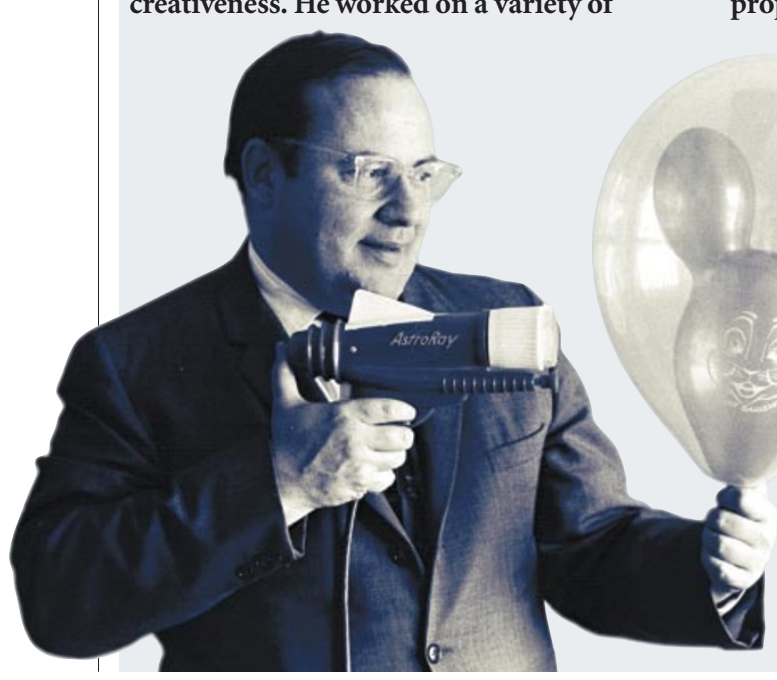

postdoctoral physicists who worked with him included Theodor
Hänsch, who with Schawlow first recognized and discussed molecular or atomic cooling with laser light. This initial idea has allowed the development of a remarkable new field of low-temperature physics, and has been applied by other physicists to produce new low-temperature states of matter.

In Schawlow's oral history, now available in research libraries, he singles out three of his scientific papers as particularly important: one on determination of nuclear size from hyperfine spectra resulting from work with Crawford at Toronto; the optical maser or laser paper; and the one on slowing down of atoms or molecules with lasers.

Schawlow's approach to science involved deep and intuitive understanding. He liked simplicity and found ways of doing powerful experiments with relatively simple elements, and of using perceptive but simple analyses of phenomena. He was renowned among friends and students for his charm and sense of humour on all occasions, and for amusing scientific demonstrations and tricks. The latter include making an edible laser of Jell-O, and using a laser to explode one balloon inside another to illustrate its selectivity.

Schawlow was also known for his research on communicating with autistic people, and for his contributions to helping them. His son is at an institution in California for people with autistic problems. The main building was donated by Arthur and named after his wife Aurelia Schawlow, who died in an automobile accident in 1991. Shortly before his own death, the institution was renamed the Arthur Schawlow Center because of his crucial role in its success.

In addition to the Nobel prize, awarded in $\mathbf{1 9 8 1}$ for his "contributions to the development of laser spectroscopy", Schawlow received many honours. He also served as president of the American Physical Society, president of the Optical Society of America and on many boards and committees that serve science and society.

The remarkable variety of contributions Schawlow made to science is already the basis of many important developments and we can expect more to come. His character, friendliness and humour will also be long remembered. He is survived by his son Arthur K. Schawlow, his daughters Helen Johnson and Edith Dwan, and by five grandchildren.

\section{Charles H. Townes}

Charles H. Townes is in the Department of Physics, University of California, Berkeley, California 94720, USA.

e-mail: cht@ssl.berkeley.edu 